\title{
Electrocatalytic dechlorination of p-chlorophenol using a 3D cathode with magnetic separable $\mathrm{Fe}_{3} \mathrm{O}_{4} @ P P y @ P d$ catalyst
}

\author{
Xuefeng Wei ${ }^{*}$ Laiyuan Zeng, Juan Miao, Ruichang Zhang, Junjie Zhang, Shuai An, Jun Zhang \\ College of Chemical Engineering \& Pharmaceutics, Henan University of Science and Technology, \\ Luoyang, 471023, P.R. China \\ *E-mail: xfwei@haust.edu.cn
}

doi: $10.20964 / 2019.12 .51$

Received: 20 June 2019 / Accepted: 27 August 2019 / Published: 29 October 2019

The magnetic separable catalyst, $\mathrm{Fe}_{3} \mathrm{O}_{4} @ \mathrm{PPy} @ \mathrm{Pd}$, was successfully prepared and characterized by scanning electron microscopy (SEM), X-ray diffraction (XRD), and inductively coupled plasmaatomic emission spectroscopy (ICP-AES). The three dimensional (3D) composite electrode was fabricated by loading the $\mathrm{Fe}_{3} \mathrm{O}_{4} @ \mathrm{PPY} @ \mathrm{Pd}$ catalyst onto a permanent magnet core@Ti housing support. The electrocatalytic hydrodechlorination of $\mathrm{p}$-chlorophenol on the 3D composite electrode in aqueous solutions was investigated, and the influences of initial $\mathrm{pH}$, the applied current and the type of aeration on the dechlorination efficiencies of p-chlorophenol were also studied. The dechlorination efficiency reached $92.3 \%$ within $120 \mathrm{~min}$, under optimum conditions, i.e., with a dechlorination current of $5 \mathrm{~mA}$, a $\mathrm{pH}$ value of 2.35 and using a supporting electrolyte of $0.05 \mathrm{~mol} / \mathrm{L} \mathrm{Na}_{2} \mathrm{SO}_{4}$ at ambient temperature. The 3D composite electrode shows promising potential for dechlorination with good stability and reusability.

Keywords: electrocatalytic dechlorination; three-dimensional electrode; polypyrrole; magnetic separable catalysts

\section{FULL TEXT}

(C) 2019 The Authors. Published by ESG (www.electrochemsci.org). This article is an open access article distributed under the terms and conditions of the Creative Commons Attribution license (http://creativecommons.org/licenses/by/4.0/). 